\title{
Avaliação da remoção adsortiva do tiofeno de uma gasolina modelo utilizando ZSM-35 impregnada com molibdênio
}

\author{
Evaluation of the adsorptive removal of thiophene from a model gasoline using ZSM-35
} impregnated with molybdenum

\author{
I. M. S. Correia ${ }^{1 *}$; A. M. G. P de Souza²; M. J. B. de Souza ${ }^{3}$; C. P. \\ Souza $^{1}$ \\ ${ }^{\text {I} P r o g r a m a ~ d e ~ P o ́ s ~ g r a d u a c ̧ a ̃ o ~ e m ~ E n g e n h a r i a ~ Q u i ́ m i c a, ~ D e p a r t a m e n t o ~ d e ~ E n g e n h a r i a ~ Q u i ́ m i c a, ~ U n i v e r s i d a d e ~}$ \\ Federal do Rio Grande do Norte, 59078-970, Natal- RN, Brasil \\ ${ }^{2}$ Departamento de Química, Universidade Federal de Sergipe, 49100-000, São Cristóvão- SE,Brasil \\ ${ }^{3}$ Departamento de Engenharia Química, Universidade Federal de Sergipe, 49100-000, São Cristóvão- SE,Brasil
}

*iaramsc.ufs@gmail.com

(Recebido em 10 de janeiro de 2018; aceito em 08 de março de 2018)

\begin{abstract}
A busca por processos alternativos para a remoção de compostos enxofre nos combustíveis é uma constante, visto que a legislação ambiental em todo o mundo está cada vez mais rigorosa quanto às reduções das frações desses compostos nos combustíveis. Este estudo avaliou a capacidade adsortiva da zeólita ZSM-35 pura e impregnada com molibdênio a $2,5 \%$ e $5 \%$ na remoção do tiofeno, composto organossulfurado, de uma gasolina modelo. Os materiais foram preparados via impregnação úmida e caracterizados por DRX, MEV, análise térmica (TG/DTG). A cinética de adsorção foi realizada nas temperaturas de $303 \mathrm{~K} \mathrm{e} 313 \mathrm{~K}$, em um sistema em batelada sob uma agitação de $140 \mathrm{rpm}$ por 12 horas. A cinética de adsorção foi avaliada pelos modelos cinéticos de peseudoprimeira ordem, pseudossegunda ordem, difusão intrapartícula e Elovich. Os resultados revelaram que o aumento da temperatura e a concentração do molibdênio na estrutura da zeólita tem influência no rendimento da remoção de enxofre da gasolina.

Palavras-chave: dessulfurização, adsorção, ZSM-35
\end{abstract}

The search for alternative processes for the removal of sulfur compounds in fuels is a constant, as environmental legislation around the world is becoming increasingly rigorous regarding reductions in the fraction of these compounds in fuels. This study evaluated the adsorptive capacity of zeolite ZSM-35 pure and impregnated with $2.5 \%$ and $5 \%$ molybdenum in the removal of the thiophene, organosulfur compound, of a model gasoline. The materials were prepared via wet impregnation and characterized by XRD, SEM, thermal analysis (TG/DTG). Adsorption kinetics were performed at temperatures of $303 \mathrm{~K}$ and $313 \mathrm{~K}$ in a batch system under agitation of $140 \mathrm{rpm}$ for 12 hours. The kinetics of adsorption was evaluated by kinetic models of pseudo first order, pseudo second order, intraparticle diffusion and Elovich. The results showed that the increase in temperature and the concentration of molybdenum in the structure of the zeolite has an influence on the increase of the sulfur removal efficiency of the gasoline.

Keywords: desulfurization, adsorption, ZSM-35

\section{INTRODUÇÃO}

Atualmente a preocupação com as emissões de poluentes para atmosfera tem estimulado o desenvolvimento de pesquisas que visam a busca por métodos e processos mais sustentáveis para atender as novas demandas da legislação ambiental em todo o mundo. Além disso, tais pesquisas podem ser direcionadas para a busca por processos que utilizem condições operacionais menos severas e mais eficientes na aplicação dos recursos naturais nos processos químicos em geral [1, 2].

No processamento de combustíveis existe uma tendência mundial para a redução de compostos poluentes, por meio de modificações constantes nas especificações dos combustíveis comercializados em várias partes do mundo. Um desses poluentes é o enxofre que é apontado como um grande fator de modificação ambiental [1], provocando o desequilíbrio atmosférico com alteração de ciclos biogeoquímicos, redução da qualidade do ar e formação da chuva ácida [2]. 
O enxofre é o elemento mais abundante no petróleo depois do carbono e hidrogênio e pode ser encontrado nas frações de petróleo sob a forma de diferentes compostos orgânicos, classificados como mercaptanas, sulfetos, dissulfetos, tiofenos, benzotiofenos e dibenzotiofenos [3]. A depleção das reservas de petróleo força o processamento de frações de petróleo cada vez mais pesadas, sendo que o petróleo dessas reservas contém uma grande quantidade de componentes sulfurados $[2,4]$. Dessa forma, os processos de tratamento que visam a remoção de heteroátomos, como o enxofre, dos combustíveis são cada vez mais importantes [4].

No refino do petróleo a hidrodessulfurização (HDS) é o processo de hidrotratamento que tem por objetivo remover compostos de enxofre dos destilados. Neste processo a carga que entra no reator é composta por naftas ou destilados, oriundos de outras unidades de processamento tais como a destilação atmosférica, destilação a vácuo ou unidade de craqueamento. O processo de hidrodessulfurização é altamente eficiente na remoção de tióis, sulfetos e dissulfetos, mas é menos eficiente para tiofenos e derivados de tiofeno [5-7,1]. Assim, os compostos de enxofre que permanecem nos combustíveis de transporte são tiofeno, benzotiofeno, dibenzotiofeno e seus derivados alquilados [1].

Na problemática que é apresentada pelos processos de hidrotratamento podem-se destacar os seguintes pontos: o alto consumo de hidrogênio e as severas condições operacionais de temperatura e pressão empregadas durante o processo para a obtenção de altas conversões, além do uso de catalisadores onerosos que são utilizados no processo [8].

Sendo assim, a viabilidade técnica de processos alternativos e/ou complementares à HDS é uma crescente no meio científico, sendo que os principais processos alternativos e/ou complementares de dessulfurização estudados visam a aplicação de processos biotecnológicos [911], utilização de processos oxidativos [12-14], e a aplicação de processos adsortivos utilizando diferentes materiais adsorventes [2, 5, 15]. A dessulfurização adsortiva recebe destaque por ser um dos métodos que utiliza condições operacionais de temperatura e pressão mais brandas [6].

Diante deste contexto, este trabalho teve por objetivo avaliar a viabilidade do processo de dessulfurização adsortiva empregando sistemas de adsorção compostos por adsorventes à base da zeólita ZSM-35 modificada com molibdênio na remoção do tiofeno contido em uma gasolina modelo empregando baixas temperaturas.

\section{MATERIAL E MÉTODOS}

A preparação dos adsorventes utilizados neste estudo obedeceu a duas etapas principais: (1) troca iônica da zeólita, (2) impregnação úmida com molibdênio.

\subsection{Troca iônica}

O processo de troca iônica para a substituição do sódio da estrutura da amostra NaZSM-35 (Zeolyst International) foi realizada de acordo a metodologia descrita por Silva (2004) [16] e seguiu as seguintes etapas: (i) Uma quantidade de zeólita foi pesada e transferida para um balão de fundo chato; (ii) Adicionou-se $250 \mathrm{~mL}$ de uma solução de cloreto de amônio (Dinâmica Química) de $1 \mathrm{~mol} / \mathrm{L}$ a $80^{\circ} \mathrm{C}$, mantendo o sistema sob agitação e refluxo por 2 horas; (iii) Após o tempo de agitação, a amostra foi filtrada à vácuo e lavada com água deionizada. A cada lavagem foi feita a identificação dos íons cloreto remanescentes na solução do filtrado com uma solução de nitrato de prata $(0,2 \mathrm{~mol} / \mathrm{L})$. A solução de nitrato de prata foi gotejada no efluente gerado, e ao gerar uma solução sem formação de precipitado, a amostra foi considerada livre de íons cloreto (Cl-). (iv). Após essa etapa a amostra foi submetida ao processo de secagem em estufa à $110^{\circ} \mathrm{C}$ por quatro horas. Posteriormente, o material foi submetido a tratamento térmico em um forno mufla, à uma taxa de aquecimento de $10^{\circ} \mathrm{C} \mathrm{min}^{-1}$, em uma atmosfera estática de ar. Ao atingir $400^{\circ} \mathrm{C}$, o sistema foi mantido nestas condições por 2 horas. 


\subsection{Impregnação com molibdênio}

Para a impregnação da zeólita ZSM-35 com molibdênio empregou-se a seguinte metodologia: i) Pesou-se a massa da zeólita, ii) Pesou-se a massa correspondente de heptamolibdato de amônio (Fluka Analytical), conforme a concentração em massa de molibdênio requerida $(2,5$ e $5 \% \mathrm{~m} / \mathrm{m})$ e dissolveu-se em água destilada; iii) Adicionou-se a solução obtida em (ii) à massa da zeólita, item (i) e em seguida homogeneizou-se a suspensão sólida (iv). Evaporouse o excesso de água em uma chapa aquecedora a $70^{\circ} \mathrm{C}$, (v). Após a evaporação do excesso de água, transferiu-se o sólido obtido para estufa para secagem a $110^{\circ} \mathrm{c}$ por 12 horas.

Após a secagem em estufa, as amostras foram calcinadas em forno mufla à uma razão de aquecimento de $10^{\circ} \mathrm{C} \mathrm{min}^{-1}$ até $550^{\circ} \mathrm{C}$ até atingir o patamar de $550^{\circ} \mathrm{C}$, onde permaneceu por 5 horas.

\subsection{Caracterização das amostras}

Os sólidos obtidos foram caracterizados pelas seguintes análises: difração de raios-X (DRX), termogravimetria (TG/DTG), fluorescência de raios-X (FRX) e microscopia eletrônica de varredura (MEV).

As análises de difração de raios-X foram realizadas utilizando um difratômetro, SHIMADZU - XRD-6000, com radiação Cuk $\alpha(\lambda=0,1542 \mathrm{~nm})$, voltagem do tubo de $40 \mathrm{kV}$ e corrente $30 \mathrm{~mA}$, com filtro de Ni. A aquisição dos dados foi realizada no intervalo de $2 \theta$ entre $5^{\circ}$ e $60^{\circ}$, com velocidade de varredura de goniômetro de $2^{\circ}$. $\min ^{-1}$ e passo de $0,02^{\circ}$.

As análises para caracterização química dos adsorventes foram realizadas em um espectrômetro de fluorescência de raios-X por energia dispersiva, SHIMADZU- EDX-720.

A avaliação térmica das amostras foi realizada em um analisador termogravimétrico e calorímetro simultâneo, da TA Instruments - SDTQ600. Para as análises foi utilizado cadinho de alumina e massa de amostra de $4 \mathrm{mg}$. A razão de aquecimento foi de $10^{\circ} \mathrm{C} / \mathrm{min}$ em atmosfera de nitrogênio com vazão de $50 \mathrm{~mL} / \mathrm{min}$, na faixa de temperatura ambiente até $1000^{\circ} \mathrm{C}$.

As micrografias das amostras foram obtidas em um microscópio de varredura HITACHI - TM 3000 com tensão de $15 \mathrm{kV}$. A etapa de preparação dos materiais para análise consistiu na deposição de uma porção de sólido sobre uma fita adesiva de carbono fixada ao porta-amostra do equipamento.

\subsection{Dessulfurização adsortiva}

\subsubsection{Preparação da gasolina modelo}

Para os ensaios de dessulfurização adsortiva foi preparado um combustível modelo, a partir da mistura de uma substância representativa de um composto organossulfurado, no caso o tiofeno $\mathrm{C}_{4} \mathrm{H}_{4} \mathrm{~S}$ (Sigma-Aldrich) como molécula modelo do contaminante e o heptano (Dinâmica Química) representando o hidrocarboneto. Essa mistura foi preparada objetivando obter uma concentração de $800 \mathrm{mg} / \mathrm{L}$ de enxofre.

\subsubsection{Cinética de adsorção do enxofre}

Os ensaios para avaliação da cinética de adsorção do enxofre da gasolina modelo foram realizados nas temperaturas de $303 \mathrm{~K}$ e $313 \mathrm{~K}$, em batelada, onde uma massa do adsorvente $(100 \mathrm{mg})$ foi colocada em contato com a gasolina contendo enxofre $(\mathrm{V}=20 \mathrm{~mL})$. Os ensaios foram realizados em uma incubadora (TECNAL TE-420) com controle de temperatura e agitação. Em tempos predefinidos, foi feita a amostragem de alíquotas que foram acondicionadas em fracos âmbar e mantidas sob refrigeração para posterior análise. Os tempos de amostragem foram: 0, 30, $60,120,240,360,480$ e $720 \mathrm{~min}$. As amostras foram analisadas em um analisador de enxofre 
total por fluorescência de ultravioleta (FUV) da Thermo Scientific - TS 3000. O tubo de combustão do equipamento foi aquecido a $1075+/-25^{\circ} \mathrm{C}$, sob atmosfera de oxigênio (435 $\mathrm{mL} / \mathrm{min}$ ) e hélio (135 mL/min). A análise foi conduzida de acordo com a norma ASTM D5443. O resultado é calculado automaticamente pelo software do equipamento e o teor de enxofre total é reportado em mg. $\mathrm{L}^{-1}$. A Tabela 1 apresenta as condições experimentais aplicadas aos ensaios do estudo cinético de adsorção do enxofre.

Tabela 1: Condições experimentais utilizadas no estudo da cinética de adsorção do tiofeno

\begin{tabular}{c|c|c|c|c}
\hline Amostra & \% Mo & Temperatura (K) & $\begin{array}{c}\text { Massa do } \\
\text { adsorvente (mg) }\end{array}$ & $\begin{array}{c}\text { Agitação } \\
\text { (RPM) }\end{array}$ \\
\hline HZSM-35 & 0 & & & 140 \\
2,5MoZSM-35 & 2,5 & $303 / 313$ & $\sim 100$ & \\
5MoZSM-35 & 5 & & & \\
\hline
\end{tabular}

A eficiência do processo de adsorção foi calculada utilizando a seguinte expressão (Equação 1):

$$
\% R=\frac{C_{0}-C}{C_{0}} .100
$$

Onde:

$\% R$ é o rendimento da adsorção,

$C_{0}\left(\mathrm{mg} \mathrm{L}^{-1}\right)$ é a concentração inicial de enxofre,

$\mathrm{C}\left(\mathrm{mg} \mathrm{L}^{-1}\right)$ é a concentração de enxofre no tempo $t$.

A capacidade de adsorção foi calculada pela expressão (Equação 2):

$$
q_{t}=\frac{\left(C_{o}-C\right) \times V}{m}
$$

Onde:

$q_{t}=$ quantidade de adsorbato por unidade de massa de material adsorvente $\left(\mathrm{mg} \mathrm{g}^{-1}\right)$

$C_{o}=$ concentração inicial de adsorbato $(\mathrm{mg} / \mathrm{L})$

$C=$ concentração final do adsorbato no tempo $t(\mathrm{mg} / \mathrm{L})$

$V=$ volume da solução $(\mathrm{L})$

$m=$ massa do material adsorvente $(\mathrm{g})$.

O comportamento do processo de adsorção do enxofre sobre os adsorventes foi analisado através dos modelos cinéticos de pseudoprimeira ordem [17], pseudossegunda ordem [18], difusão intrapartícula [19] e o modelo de Elovich [20]. A Tabela 2 apresenta as equações linearizadas dos modelos utilizados para avaliar o processo. 
Tabela 2: Equações dos modelos cinéticos de adsorção.

\begin{tabular}{c|c}
\hline Modelo & Equação \\
\hline Pseudoprimeira ordem & $\ln \left(q_{e}-q_{t}\right)=\ln q_{e}-k_{1} t$ \\
\hline Pseudossegunda ordem & $\frac{t}{q_{t}}=\frac{1}{k_{2} q_{e}^{2}}+\frac{t}{q_{e}}$ \\
\hline Difusão intrapartícula & $q_{t}=k_{q} \sqrt{t}+C$ \\
\hline Elovich & $q_{t}=\beta \ln (\alpha \beta)+\beta \ln (t)$ \\
\hline
\end{tabular}

\section{RESULTADOS E DISCUSSÃO}

\subsection{Troca iônica e caracterização dos sólidos adsorventes.}

\subsubsection{Troca iônica e impregnação do molibdênio}

Por meio da análise de fluorescência de raios-X pode-se concluir que os ensaios de troca iônica para remoção do Na presente na estrutura da zeólita foram favoráveis, pois a presença deste não foi detectada na amostra HZSM-35. No procedimento de impregnação da zeólita com molibdênio foi obtido sólidos com um teor de 2,34\% de molibdênio para a amostra 2,5MoZSM-35 e 5,87\% para a amostra 5MoZSM-35.

\subsubsection{Difração de raios- $X$}

Os difratogramas das amostras analisadas são apresentados nas Figuras de 1 a 2 . Analisando os difratogramas obtidos pode-se observar que ocorreu uma variação na intensidade dos picos característicos da ZSM-35 que segundo a literatura ocorrem a 9,4 $4^{\circ}$ e entre 20-30 ${ }^{\circ}$ [21 -26]. Assim pode-se inferir que o processo de impregnação afetou a critalinidade do material, mantendo a sua estrutura ordenada.

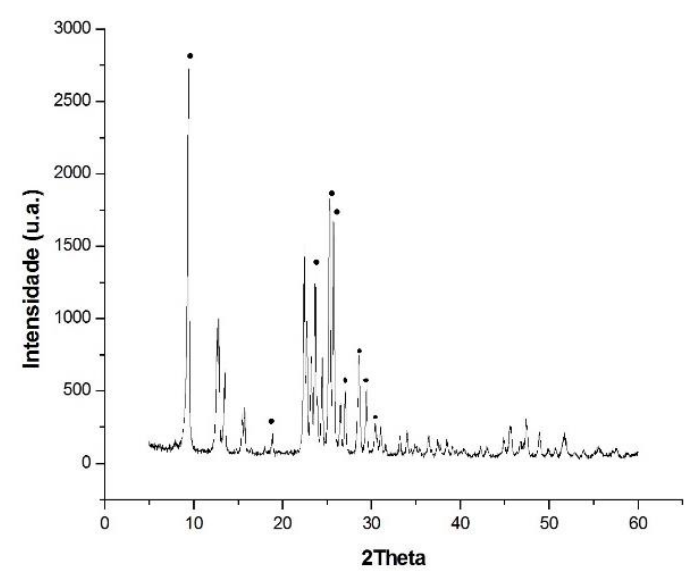

Figura 1: Difratograma da amostra HZSM-35. 

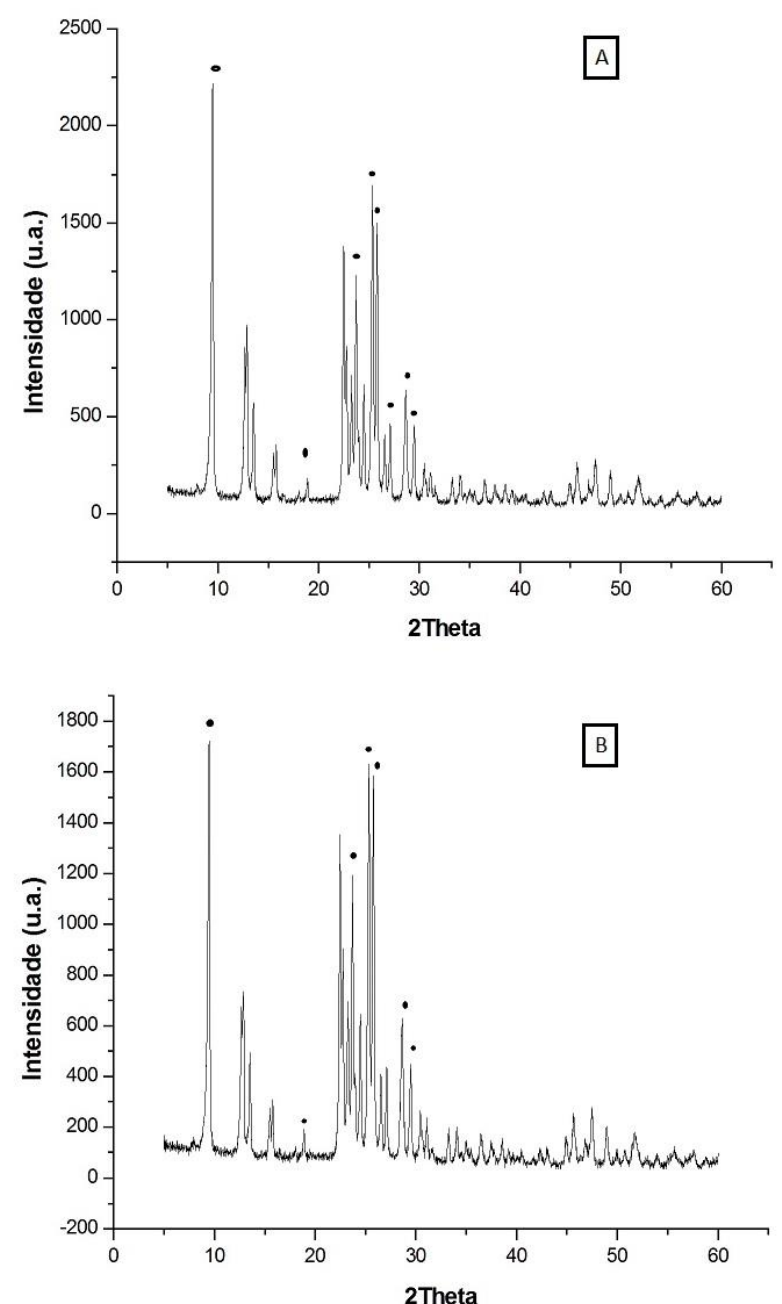

Figura 2: Difratogramas das amostras 2,5MoZSM-35 (A) e 5MoZSM-35 (B).

\subsubsection{Microscopia eletrônica de varredura}

As micrografias da ZSM35 pura e impregnada com molibdênio são apresentadas nas Figuras 3 a 5.

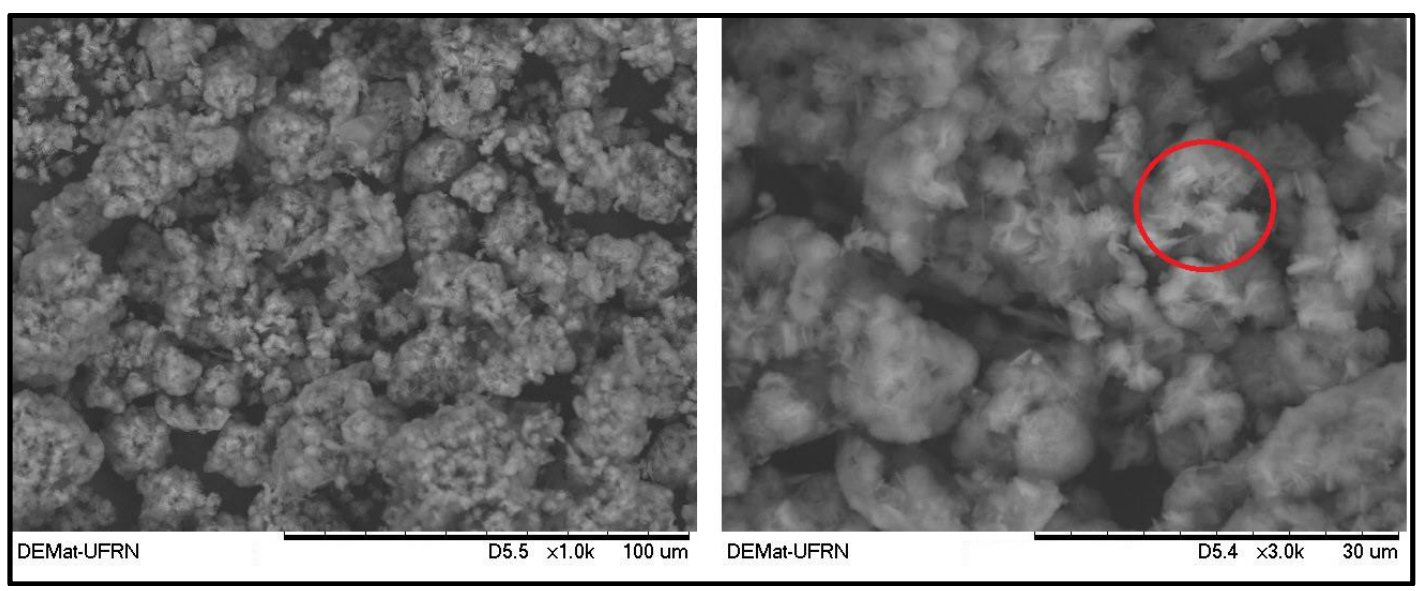

Figura 3: Micrografias do adsorvente HZSM-35.

Na micrografia da amostra HZSM-35 (Figura 3) pode-se observar a formação de agregados esféricos com estruturas com morfologia que se assemelham a pequenas agulhas distribuídas em alguns pontos da amostra. 
Verifica-se também que a impregnação de molibdênio na zeólita ZSM-35 provocou um aumento na heterogeneidade dos aglomerados e no tamanho das partículas, como observado nas Figuras 4 e 5 para as amostras 2,5MoZSM35 e 5MoZSM35, respectivamente. De acordo com Montañez et al. (2014) [27] a natureza dos precursores utilizados na impregnação pode influenciar na dispersão e tamanho das partículas dos óxidos metálicos na superfície dos suportes adsorventes. Segundos os autores, quando a sinergia entre estes é fraca, há a formação de cristais grandes na superfície externa, influenciando no grau de dispersão do metal no suporte.

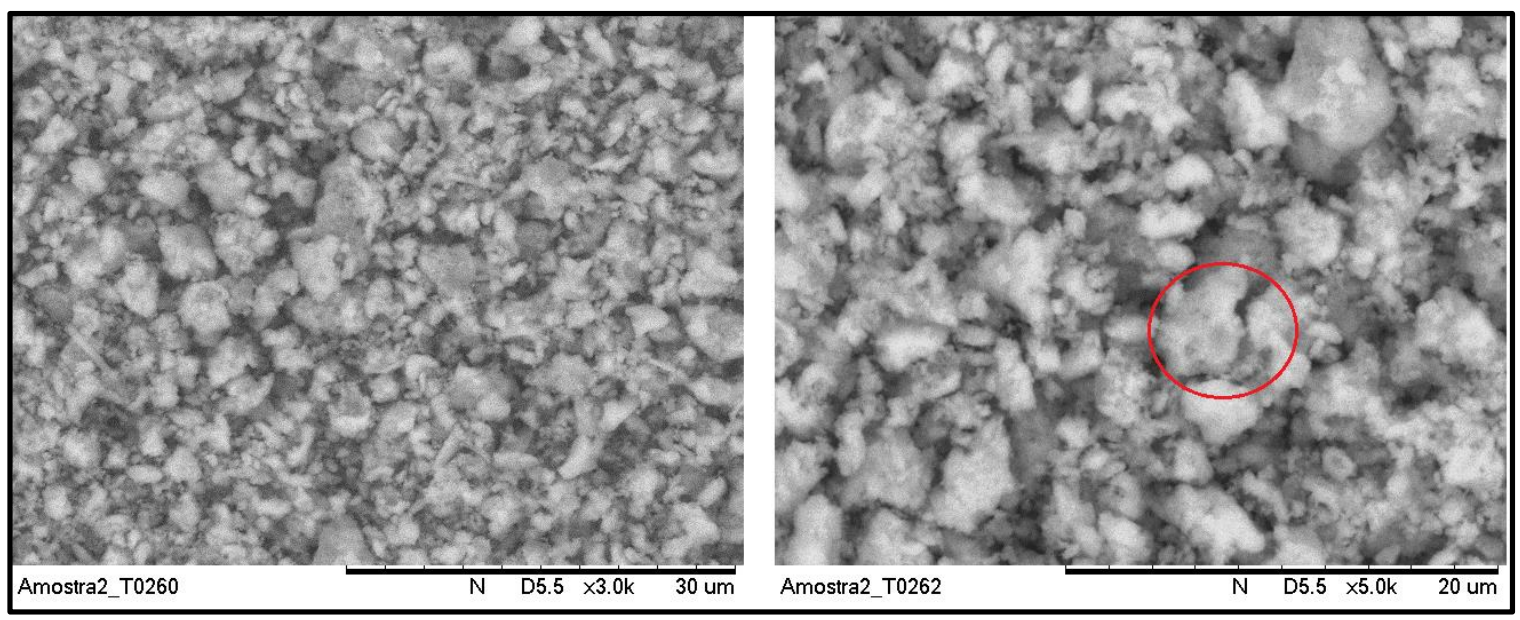

Figura 4: Micrografias do adsorvente 2,5MoZSM-35.

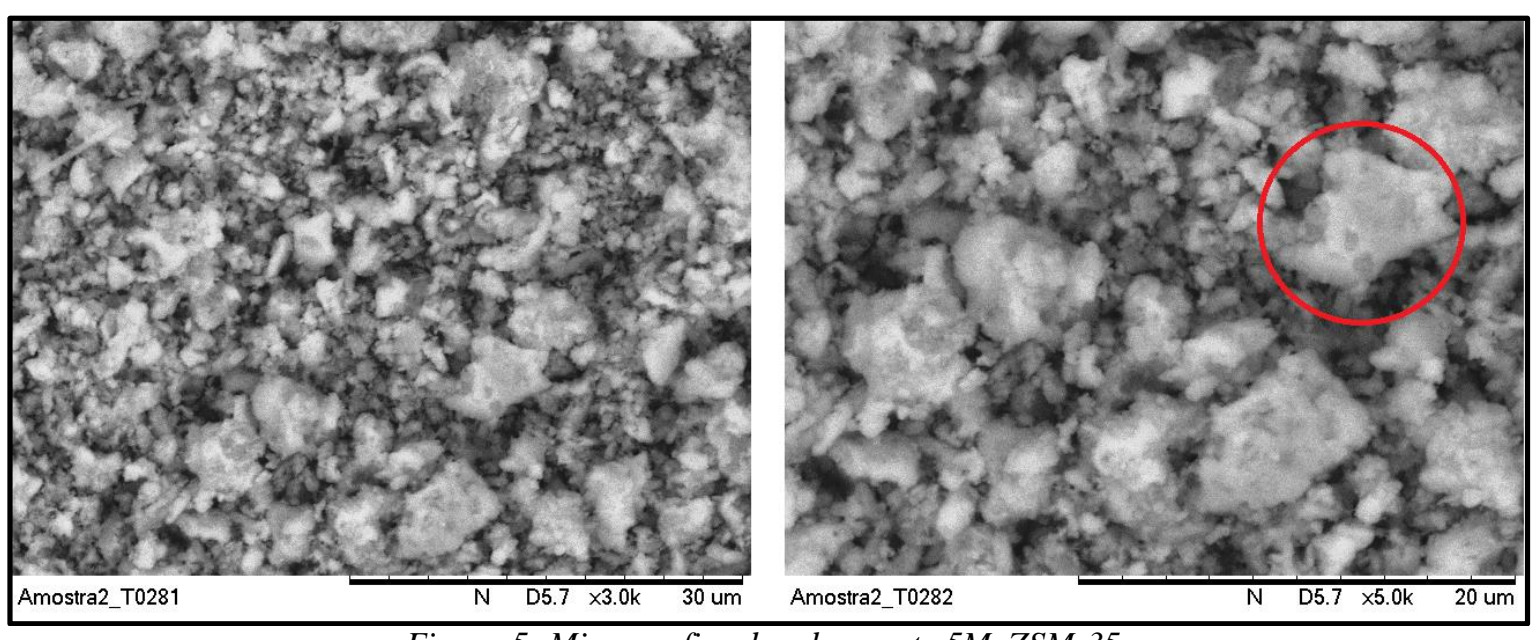

Figura 5: Micrografias do adsorvente 5MoZSM-35.

\subsubsection{Análises térmicas (TG/DTG)}

A análise termogravimétrica dos adsorventes permitiu avaliar o efeito da variação da concentração de molibdênio na estabilidade térmica da zeólita por meio da avaliação da variação de perda de massa apresentadas pelos sólidos até a temperatura de $1000^{\circ} \mathrm{C}$. As Figuras de 6 a 8 apresentam as curvas TG/DTG com o comportamento da decomposição térmica desses materiais. 


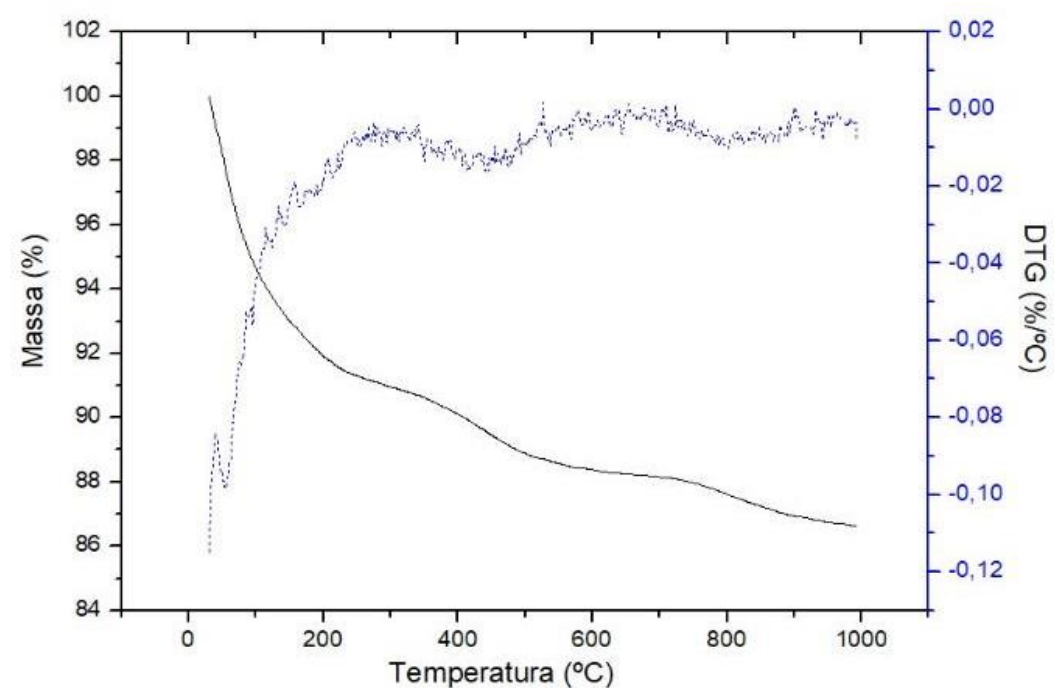

Figura 6: Curva TG/DTG da amostra HZSM-35.

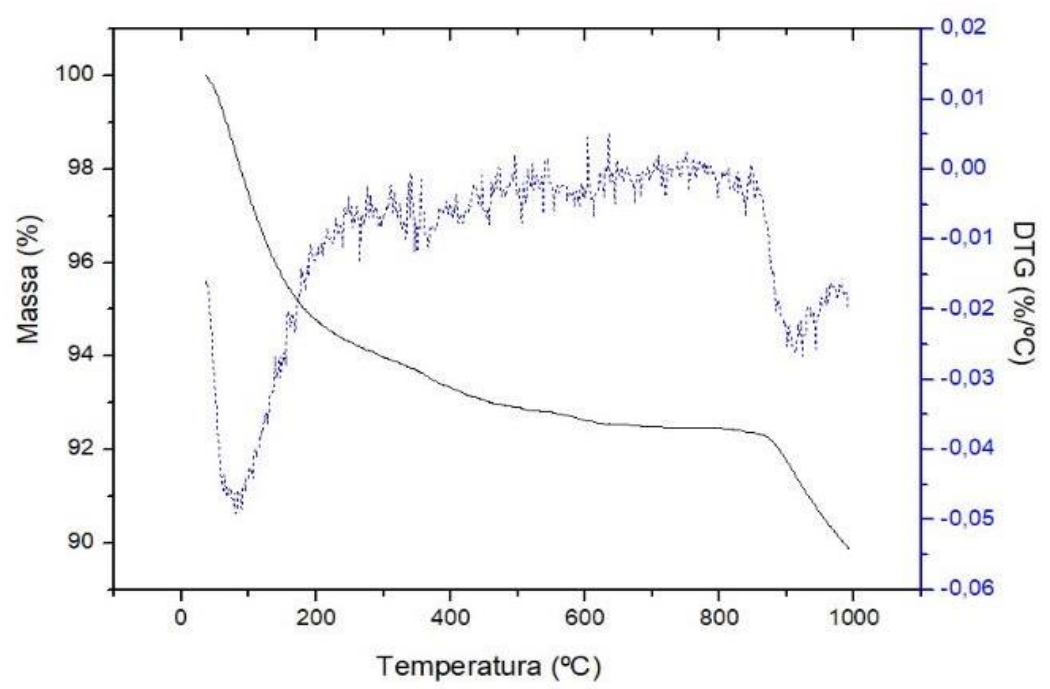

Figura 7: Curva TG/DTG da amostra 2,5MoZSM-35.

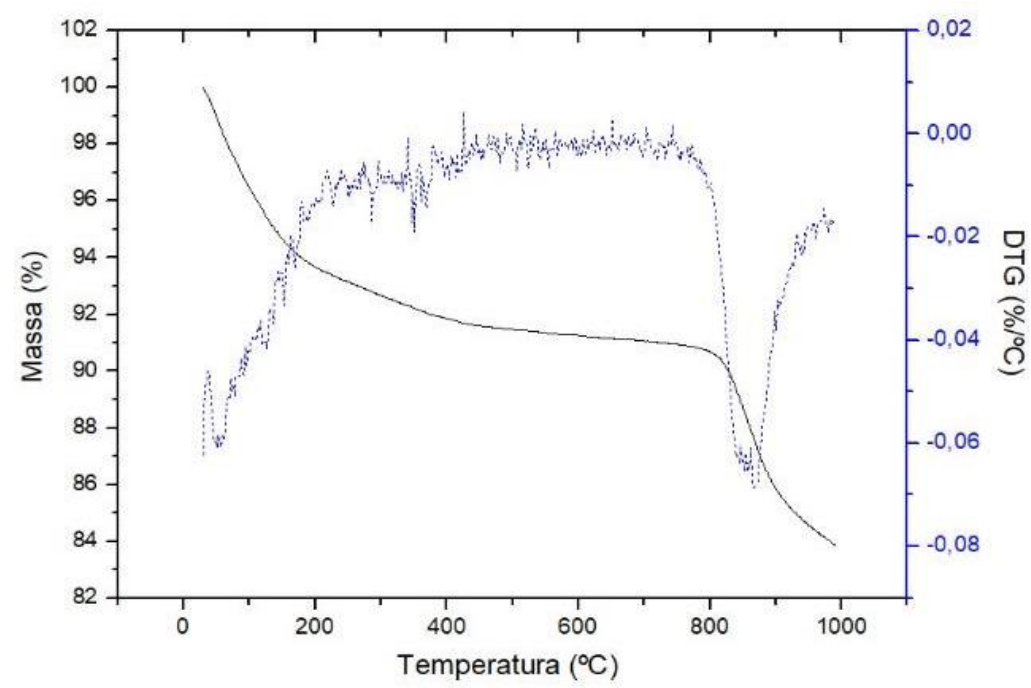

Figura 8: Curva TG/DTG da amostra 5MoZSM-35. 
Os materiais apresentaram perfis de decomposição térmica distintos com diferentes estágios de decomposição térmica. A Tabela 3 apresenta a quantificação de perda de massa das amostras em cada etapa de decomposição e as respectivas faixas de temperatura.

Tabela 3: Faixas de temperatura e percentuais de perdas de massa para os adsorventes avaliados obtidas a partir das curvas TG/DTG.

\begin{tabular}{c|c|c|c|c|c|c}
\hline Amostra & \multicolumn{3}{|c|}{ Temperatura $\left({ }^{\circ}\right.$ C) } & \multicolumn{3}{c}{ Perda de massa (\%) } \\
\hline Evento & (I) & (II) & (III) & (I) & (II) & (III) \\
\hline HZSM35 & $30-244$ & $244-990$ & - & 8,65 & 4,71 & - \\
\hline 2,5 MoZSM35 & $30-246$ & $246-855$ & $855-990$ & 5,67 & 1,99 & 2,44 \\
\hline 5MoZSM35 & $30-219$ & $219-788$ & $788-990$ & 6,47 & 2,74 & 6,97 \\
\hline
\end{tabular}

A amostra pura (HZSM35) teve uma perda de massa total de 13,36\% que ocorreu em dois estágios de decomposição. O primeiro evento ocorreu na faixa de temperatura entre $30^{\circ} \mathrm{C}-244^{\circ} \mathrm{C}$, com uma perda de massa igual a $8,65 \%$ e uma segunda que ocorreu a uma temperatura entre $244^{\circ} \mathrm{C}-990^{\circ} \mathrm{C}$ com uma perda de $4,71 \%$. A partir dos dados apresentados na Tabela 3 pode-se observar que a impregnação com $2,5 \%$ de molibdênio provocou um aumento da estabilidade térmica do material quando comparado com a amostra pura. $\mathrm{O}$ incremento de molibdênio em 2,5\% (2,5MoZSM35) modificou o perfil de decomposição térmica que apresentou três estágios de perda de massa, a primeira ocorreu entre $30^{\circ} \mathrm{C}-246^{\circ} \mathrm{C}$ com uma perda de $5,67 \%$, a segunda entre $246^{\circ} \mathrm{C}-885^{\circ} \mathrm{C}$ com uma perda de $1,99 \%$ e a terceira entre $855^{\circ} \mathrm{C}-990^{\circ} \mathrm{C}$ com uma perda de $2,44 \%$ em relação a massa inicial. A perda de massa total foi de $10,1 \%$. Para a amostra 5MoZSM35 observa-se que a perda de massa também ocorre em três estágios de decomposição, com a redução dos limites de temperatura onde essas perdas de massa ocorrem. Nessas faixas de temperatura ocorreram maiores frações de perda, quando comparado com a amostra 2,5MoZSM35. A perda de massa total para a faixa de temperatura avaliada foi igual a $16,18 \%$.

As perdas de massa total dos adsorventes avaliados estão sumarizadas na Tabela 4.

Tabela 4: Quantificação de perda de massa total obtida da curva TG/DTG.

\begin{tabular}{c|c}
\hline Amostra & Perda de massa total \\
\hline HZSM35 & $13,36 \%$ \\
2,5MoZSM35 & $10,1 \%$ \\
5MoZSM35 & $16,18 \%$ \\
\hline
\end{tabular}

Em geral os estágios decomposição térmica para esses materiais estão associadas aos seguintes eventos: (i) o primeiro evento ocorre da temperatura ambiente até aproximadamente $250^{\circ} \mathrm{C}$ e está associado à dessorção de água, (ii) o segundo ocorre entre $300^{\circ} \mathrm{C}$ e $600^{\circ} \mathrm{C}$ e pode ser atribuída a dessorção de amônia remanescente na estrutura e (iii) está associada a dessorção de água proveniente da liberação de hidroxilas estruturais (etapa de desidroxilação).

\subsection{Dessulfurização adsortiva}

\subsubsection{Cinética de adsorção}

O efeito do tempo no processo de adsorção do enxofre é apresentado nas Figuras 9 e 10 onde estão representadas as curvas da cinética de adsorção do enxofre da gasolina utilizando os adsorventes nas temperaturas $303 \mathrm{~K}$ e $313 \mathrm{~K}$ respectivamente. As Figuras mostram que a performance da dessulfurização melhora com o aumento do tempo de contato entre o adsorvente e o adsorbato e com o aumento da temperatura. Avaliando o efeito do tempo no processo de 
adsorção, pode-se observar que o tempo de equilíbrio foi de aproximadamente 8 horas para todos os sistemas avaliados, após esse tempo a fração de enxofre removida não foi significativa. Quanto a cinética de adsorção, as amostras HZSM35 e 5MoZSM35 apresentaram maiores taxas de remoção nos primeiros tempos de processo, enquanto que a amostra 2,5MoZSM35 apresentou taxas menores para os tempos inicias.
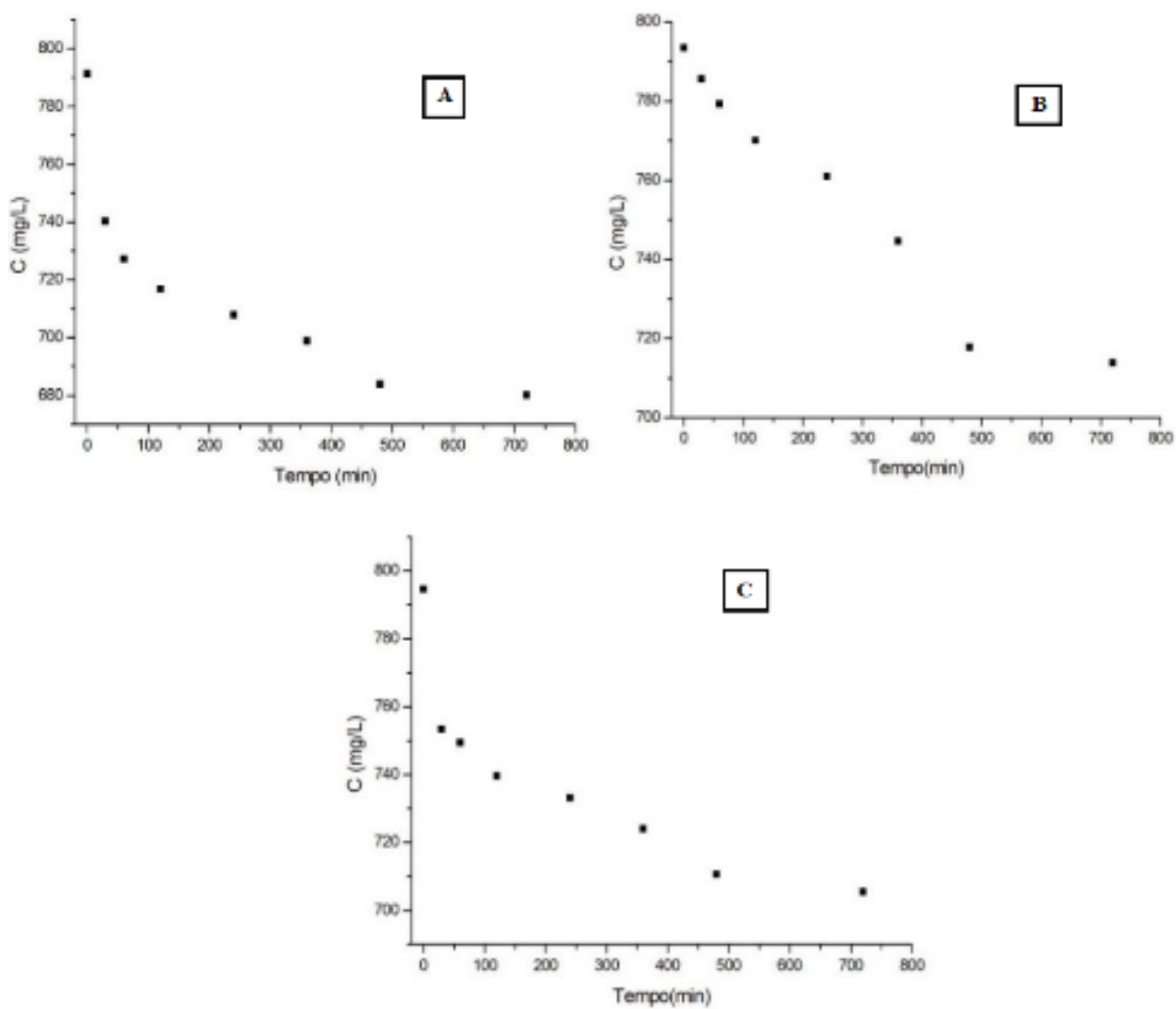

Figura 9: Cinética de adsorção do enxofre à 303 K (A) HZSM35 (B) 2,5MoZSM35 e (C) 5MoZSM35.
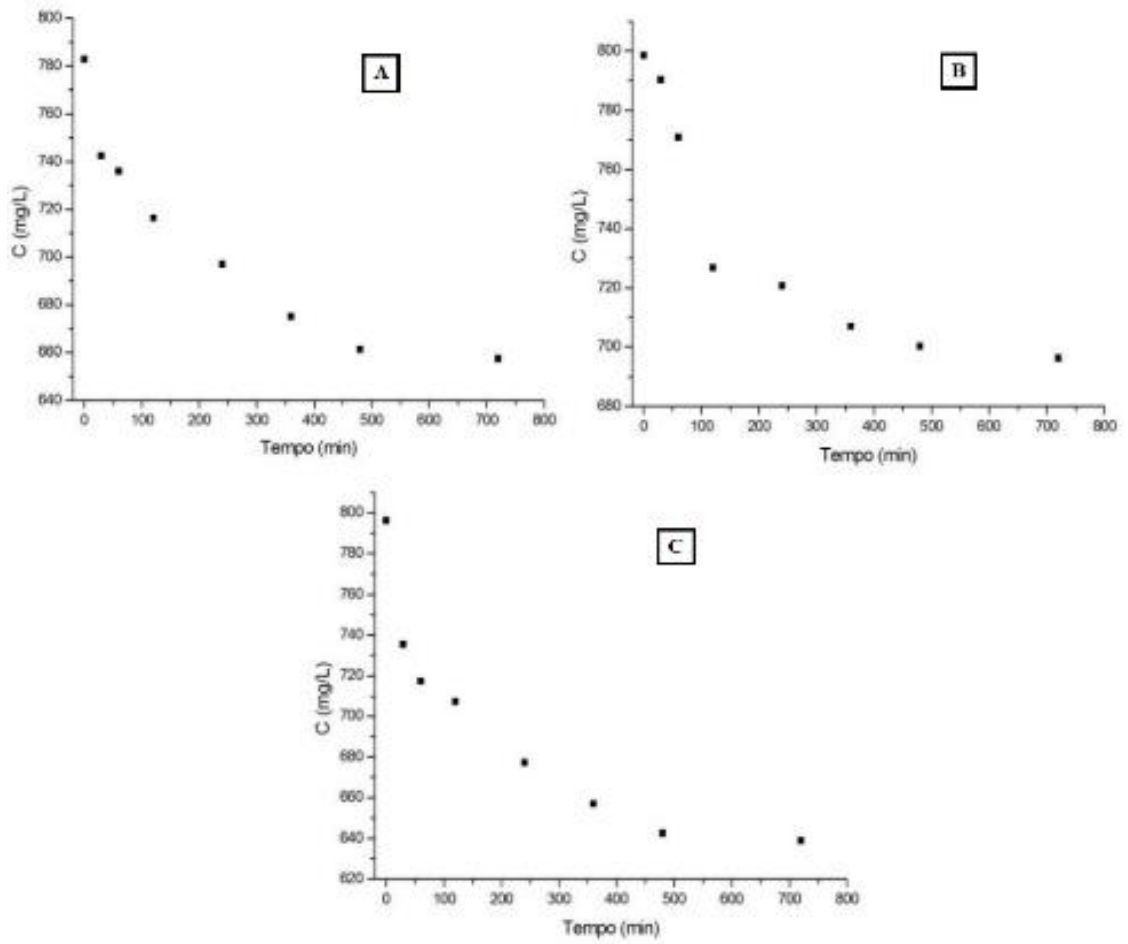

Figura 10: Cinética de adsorção do enxofre à 313K (A) HZSM35 (B) 2,5MoZSM35 e (C) 5MoZSM35. 


\subsubsection{Influência do teor de molibdênio e da temperatura na adsorção do enxofre}

Os ensaios de adsorção revelaram a importante contribuição da temperatura e do teor de molibdênio no processo de remoção do enxofre da gasolina. A Figura 11 apresenta o gráfico com os rendimentos de adsorção para as temperaturas de $303 \mathrm{~K}$ e $313 \mathrm{~K}$.

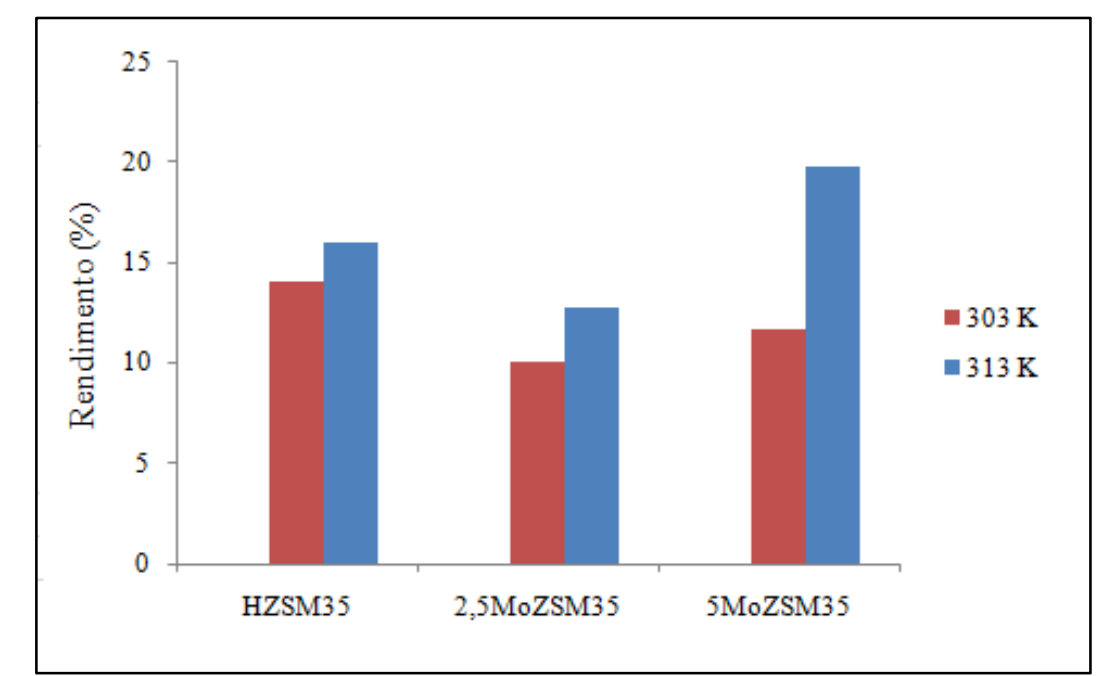

Figura 11: Rendimento da adsorção do enxofre para as temperaturas de $303 \mathrm{~K}$ e $313 \mathrm{~K}$.

Para a temperatura de $303 \mathrm{~K}$ pode-se observar que o maior rendimento da extração por adsorção foi obtido para a amostra HZSM35, provavelmente associada a uma maior acessibilidade das moléculas de tiofeno às cavidades da zeólita. De acordo com Barros (2007) [28] e Yu et al. (2002) [29] o tiofeno deve adsorver primeiramente sobre as hidroxilas da superfície zeolítica por interação eletrofílica, para depois sofrer a abertura do anel, e assim as espécies decompostas são aderidas na zeólita.

Para a adsorção realizada à $313 \mathrm{~K}$ observa-se a influência da temperatura no processo em todos os sistemas com o aumento da taxa de remoção de enxofre em 2\% para a HZSM35, 2,76\% para amostra 2,5MoZSM35 e 8,02\% para a amostra 5MoZSM35. Para a amostra 5MoZSM35 o aumento da taxa de remoção é mais pronunciado passando de $11,72 \%$ a $303 \mathrm{~K}$ para $19,74 \%$ a $313 \mathrm{~K}$, aumento influenciado pela natureza endotérmica do processo e pelo molibdênio presente na estrutura. Para o sistema adsortivo composto 5MoZSM35 /313 K, a ação do molibdênio e o aumento da temperatura atuaram sinergicamente para o aumento da taxa de remoção do enxofre.

De acordo com Yang et al. (2003) [1] a existência de metais de transição na superfície do adsorvente provoca uma melhoria no processo de adsorção pois ocorre a formação de ligações de complexação $\pi$ entre o adsorvente e o adsorbato e ainda de acordo com Al-Yassir et al. (2006) [30] a incorporação molibdênio nos adsorventes zeolíticos, promove a geração de sítios de Brönsted resultante da interação entre as espécies molibdato e as hidroxilas presentes na superfície do suporte zeolítico, o que pode promover uma melhoria na eficiência da adsorção reativa. Essas afirmações só puderam ser observadas para o sistema 5MoZSM35 /313 K.

Avaliando isoladamente o incremento do teor de metal na estrutura da zeólita, observa-se que o teor de $2,5 \%$ de molibdênio não melhorou o processo de remoção de enxofre, este fato pode estar relacionado à menor concentração de metal e/ou a ocorrência de bloqueio de cavidades da zeólita. Para a amostra 5MoZSM35 (à $303 \mathrm{~K}$ ) verifica-se o que o aumento de molibdênio na estrutura do adsorvente provocou um aumento considerável na remoção de enxofre quando comparado com a amostra 2,5MoZSM35, mas ainda abaixo do valor obtido pela amostra HZSM35(à $303 \mathrm{~K}$ ), o efeito do mecanismo de complexação $\pi$ atuou de forma mais pronunciada quando da associação das condições de concentração de metal e temperatura mais elevada, assim os elétrons $\pi$ do metal interagem com maior eficiência com os elétrons do tiofeno.

Avaliando o efeito da temperatura nas taxas de remoção obtidas, pode-se inferir que processo de adsorção para os sistemas avaliados apresenta uma natureza endotérmica, ou seja, que o aumento da temperatura favorece a remoção de enxofre do combustível nas condições de estudo. 
A Tabela 5 apresenta a influência da temperatura nos valores das capacidades adsorção dos materiais estudados para o tempo de contato de 8 horas.

Tabela 5: Influência da temperatura $(K)$ na capacidade de adsorção para os adsorventes HZSM35, 2,5MoZSM35 e 5MoZSM35.

\begin{tabular}{c|c|c}
\hline \multirow{2}{*}{ Adsorvente } & \multicolumn{2}{|c}{ Capacidade de adsorção $(\mathbf{m g} / \mathbf{g})$} \\
\cline { 2 - 3 } & $303 K$ & $313 K$ \\
\hline HZSM35 & 1,59 & 1,79 \\
2,5MoZSM35 & 1,12 & 1,45 \\
5MoZSM35 & 1,24 & 2,26 \\
\hline
\end{tabular}

\subsection{Modelagem cinética da adsorção.}

A avaliação dos dados experimentais por meio dos modelos cinéticos permite um melhor entendimento do processo de adsorção, deste modo os dados experimentais da cinética de adsorção do enxofre foram avaliados pelos modelos cinéticos de pseudoprimeira ordem, pseudossegunda ordem, difusão intrapartícula e pelo modelo de Elovich.

As Figuras 12 a 14 apresentam as curvas ajustadas para os modelos cinéticos para a adsorção de enxofre da gasolina à temperatura de $303 \mathrm{~K}$ e as Figuras 15 a 17 o ajuste para a adsorção a 313 K.
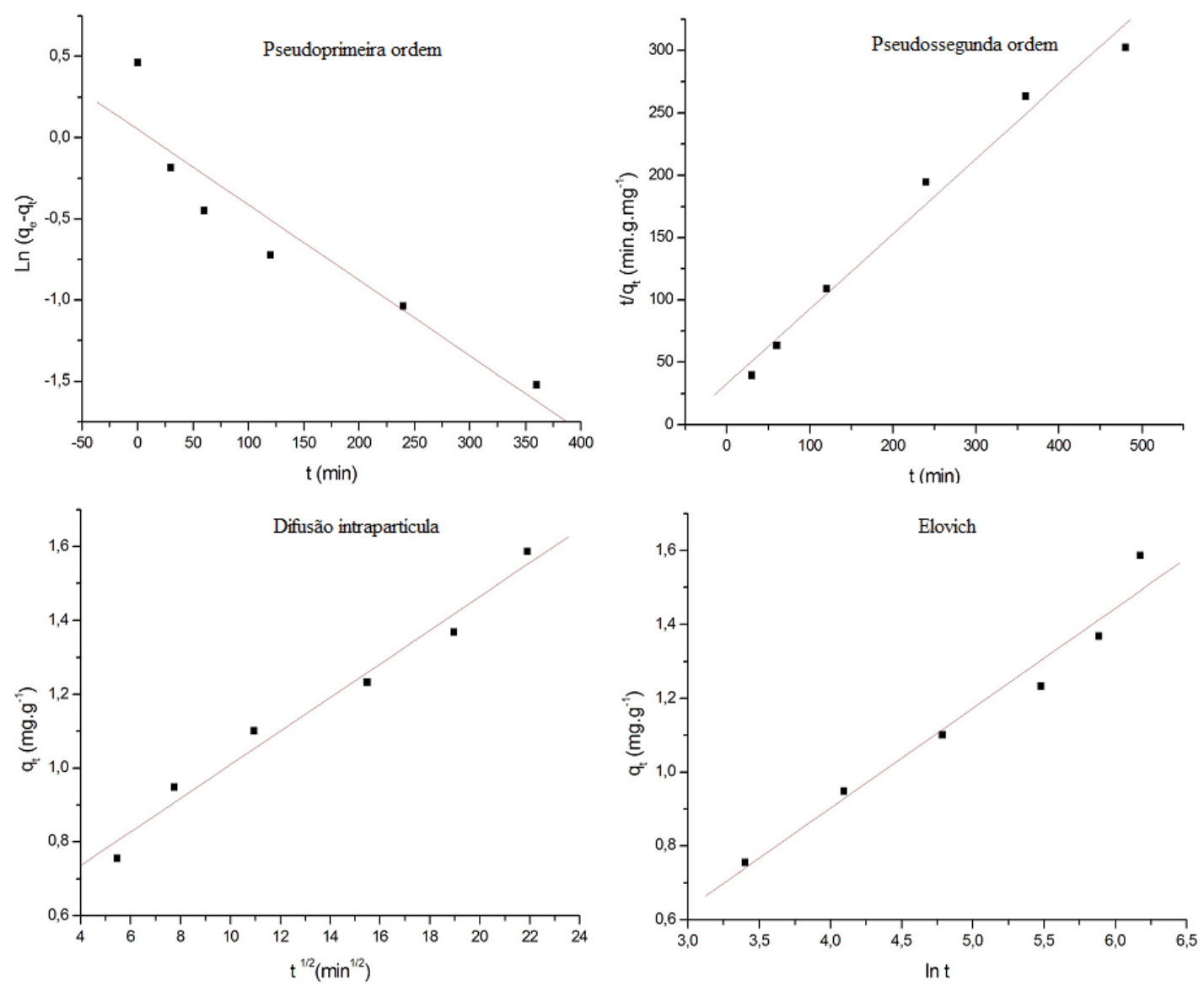

Figura 12: Ajuste dos modelos cinéticos para a amostra HZSM35, T=303K 

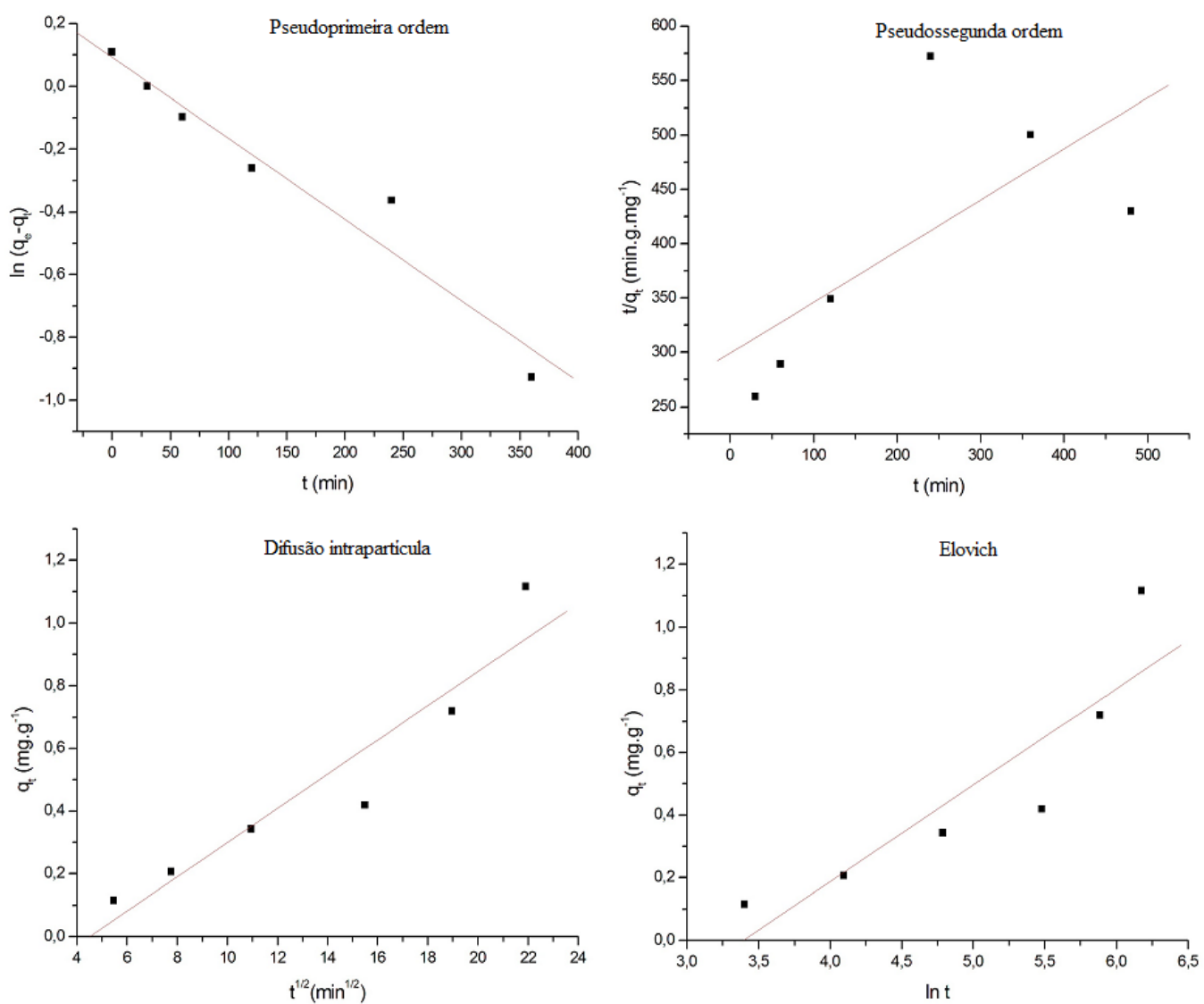

Figura 13: Ajuste dos modelos cinéticos para a amostra 2,5MoZSM35, T=303K
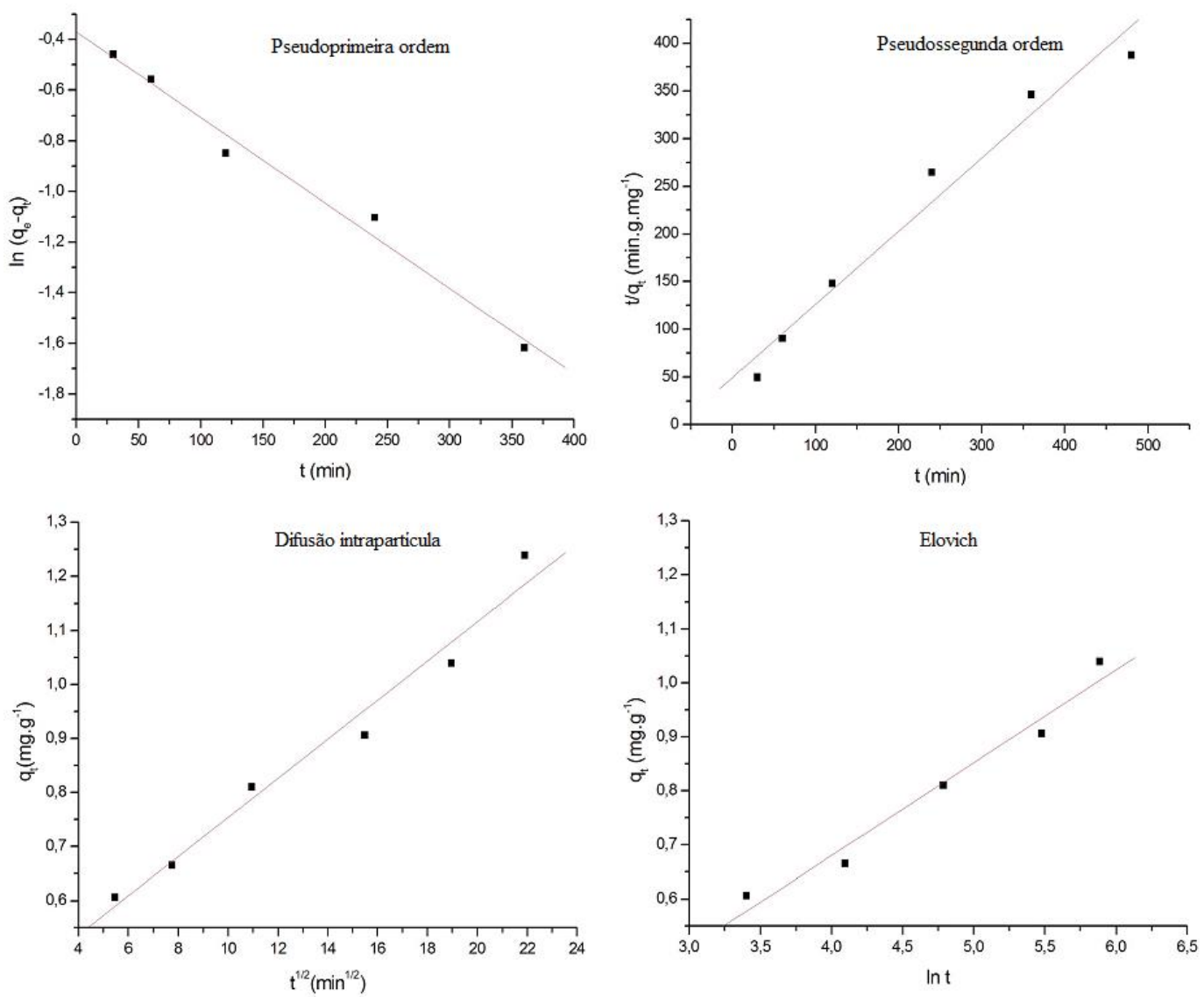

Figura 14: Ajuste dos modelos cinéticos para a amostra 5MoZSM35, T=303K 

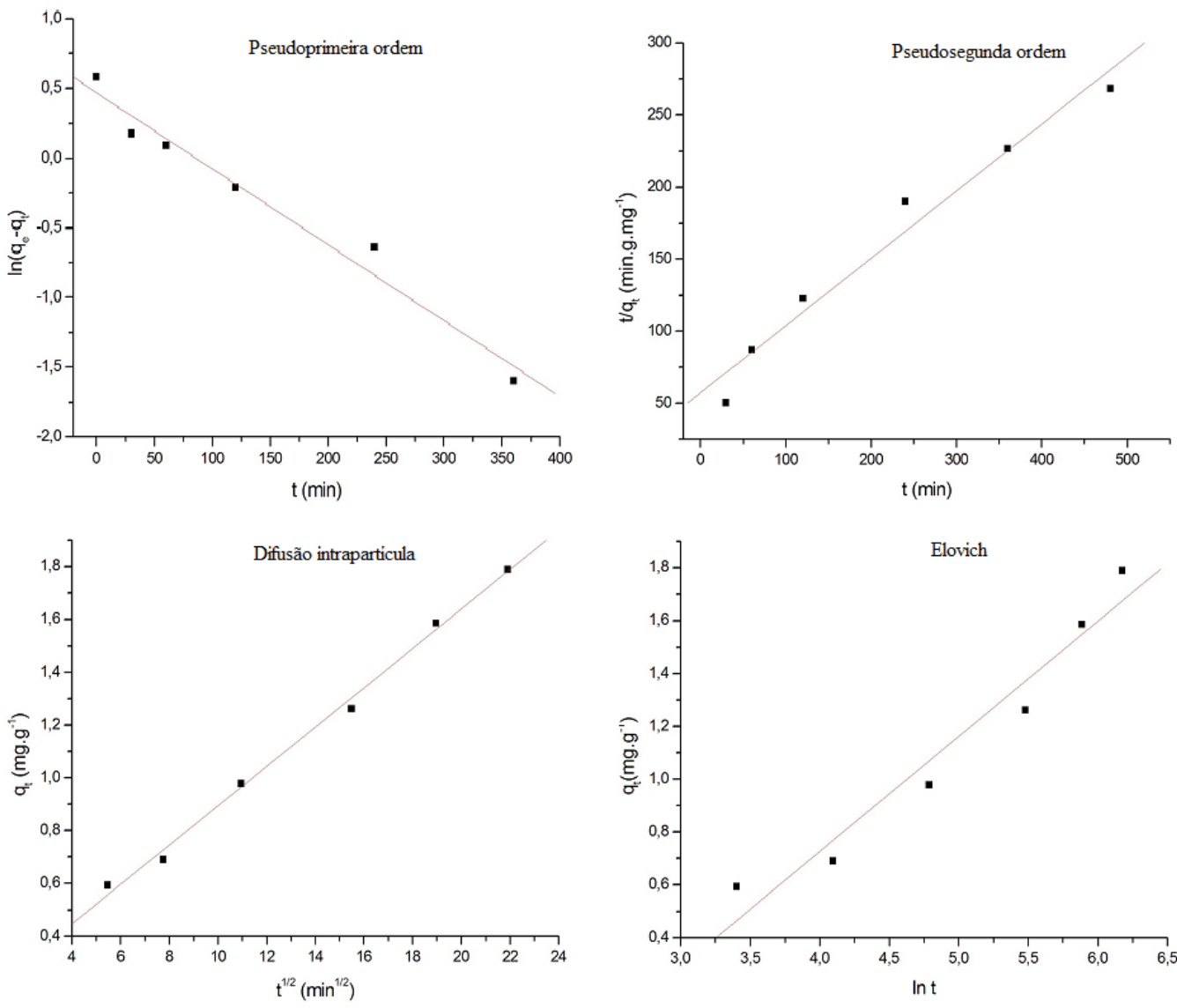

Figura 15: Ajuste dos modelos cinéticos para a amostra HZSM35, T=313K
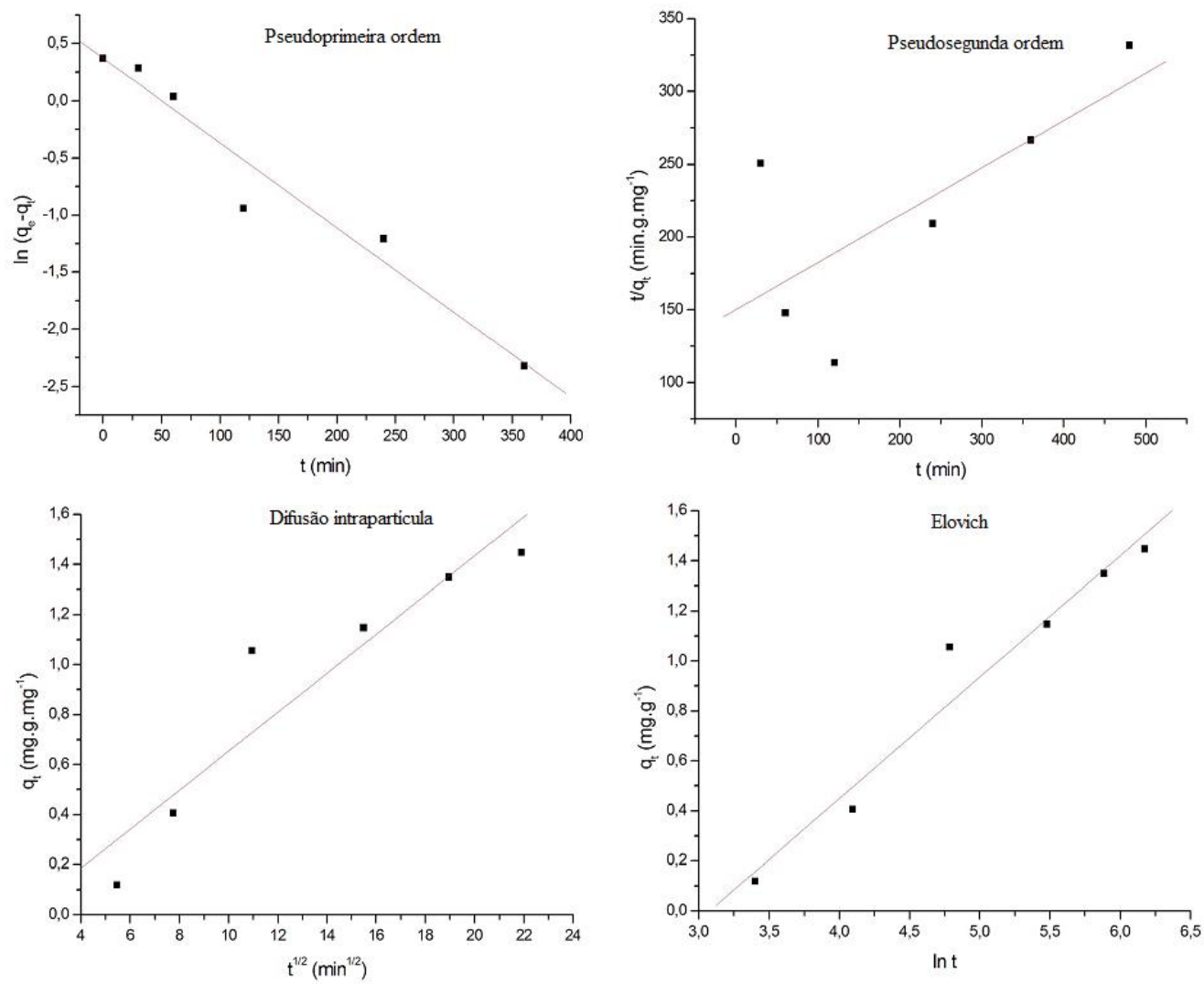

Figura 16: Ajuste dos modelos cinéticos para a amostra 2,5MoZSM35, $T=313 \mathrm{~K}$ 

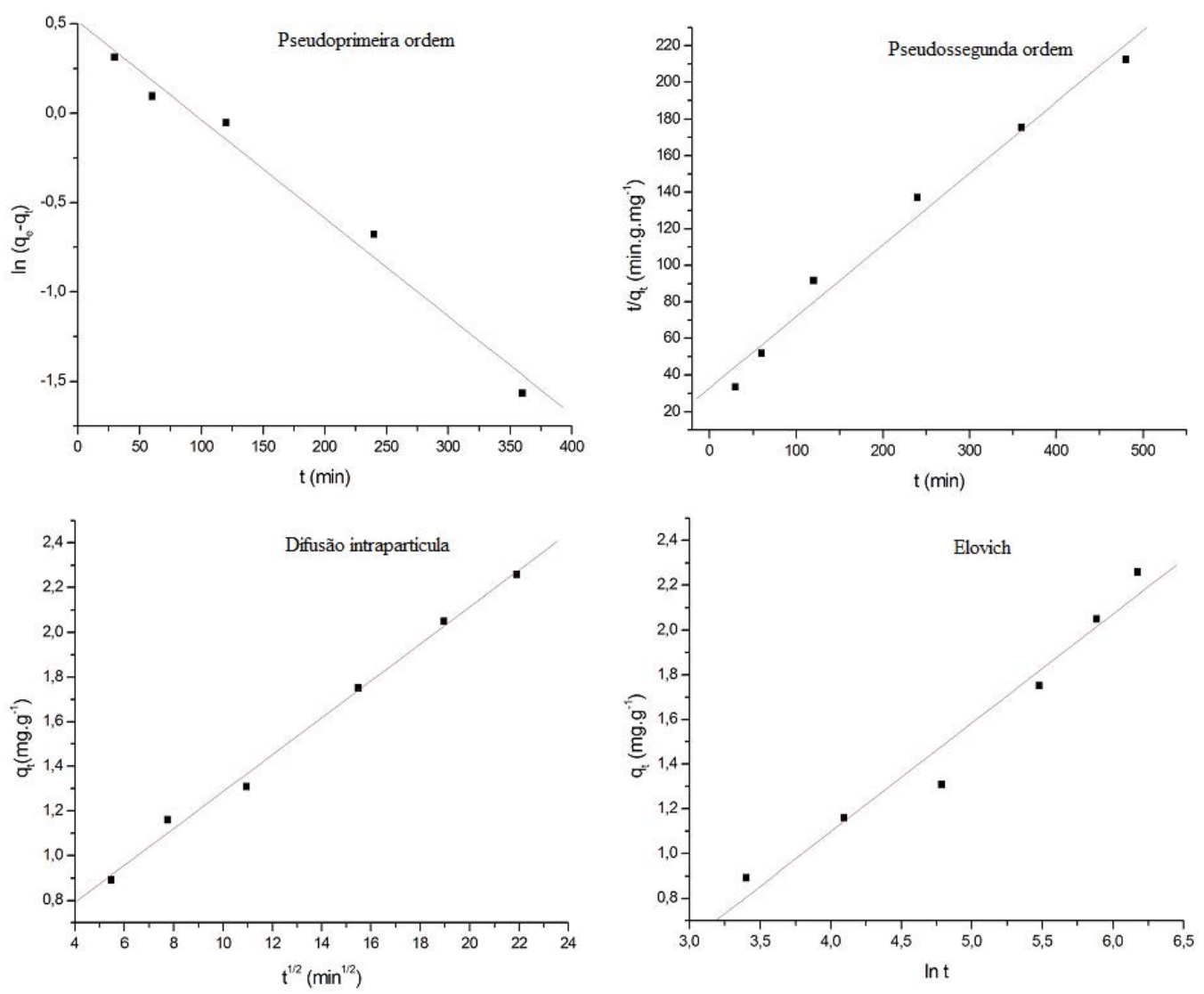

Figura 17: Ajuste dos modelos cinéticos para a amostra 5MoZSM35, T=313K

Os valores calculados dos parâmetros cinéticos para os sistemas avaliados estão apresentados na Tabela 5 e 6 para a remoção do enxofre na gasolina modelo à $303 \mathrm{~K}$ e $313 \mathrm{~K}$ respectivamente. Os modelos foram avaliados pela análise comparativa entre os coeficientes de correlação linear $\left(\mathrm{R}^{2}\right)$ obtidos pelo ajuste dos dados experimentais e os valores de $q_{e}$ calculados pelo modelo.

Tabela 5: Parâmetros cinéticos para remoção adsortiva do enxofre à $303 \mathrm{~K}$.

\begin{tabular}{|c|c|c|c|c|}
\hline \multicolumn{5}{|c|}{ Pseudoprimeira ordem } \\
\hline & $k_{1}\left(\min ^{-1}\right)$ & $q_{e \text { calc }}\left(\mathrm{mg} \mathrm{g}^{-1}\right)$ & $q_{e \exp }\left(\mathrm{mg} \mathrm{g}^{-1}\right)$ & $\mathrm{R}^{2}$ \\
\hline HZSM35 & $4,65 \times 10^{-3}$ & 1,05 & 1,59 & 0,938 \\
\hline 2,5MoZSM35 & $2,59 \times 10^{-3}$ & 1,10 & 1,12 & 0,971 \\
\hline 5MoZSM35 & $3,38 \times 10^{-3}$ & 1,45 & 1,24 & 0,993 \\
\hline \multicolumn{5}{|c|}{$\begin{array}{l}\text { Pseudossegunda ordem } \\
\end{array}$} \\
\hline & $k_{2}\left(\mathrm{~g} \cdot \mathrm{mg} \mathrm{min}{ }^{-1}\right)$ & $q_{e}$ calc $\left(\mathrm{mg} \mathrm{g}^{-1}\right)$ & $q_{e \exp }\left(\mathrm{mg} \mathrm{g}^{-1}\right)$ & $\mathrm{R}^{2}$ \\
\hline HZSM35 & $8,44 \times 10^{-2}$ & 1,66 & 1,59 & 0,991 \\
\hline 2,5MoZSM35 & $1,51 \times 10^{-2}$ & 2,13 & 1,12 & 0,68 \\
\hline 5MoZSM35 & $3,45 \times 10^{-2}$ & 1,31 & 1,24 & 0,985 \\
\hline \multicolumn{5}{|c|}{ Difusão intrapartícula } \\
\hline & $k_{D I F}\left(\mathrm{mg} \cdot \mathrm{g}^{-1} \cdot \mathrm{min}^{-0,5}\right)$ & $C\left(\mathrm{mg} \mathrm{g}^{-1}\right)$ & $\mathrm{R}^{2}$ & \\
\hline HZSM35 & $4,56 \times 10^{-2}$ & 0,55 & 0,988 & \\
\hline 2,5MoZSM35 & $5,45 \times 10^{-2}$ & 0,25 & 0,948 & \\
\hline 5MoZSM35 & $3,62 \times 10^{-2}$ & 0,39 & 0,987 & \\
\hline \multicolumn{5}{|c|}{ Elovich } \\
\hline & $\alpha\left(\mathrm{mg} \mathrm{g}^{-1} \min ^{-1}\right)$ & $\beta\left(\right.$ g. $\left.\mathrm{mg}^{-1}\right)$ & $\mathrm{R}^{2}$ & \\
\hline HZSM35 & 1,889 & 0,271 & 0,981 & \\
\hline 2,5MoZSM35 & 0,110 & 0,308 & 0,893 & \\
\hline 5MoZSM35 & 5,564 & 0,172 & 0,984 & \\
\hline
\end{tabular}


Tabela 6: Parâmetros cinéticos para remoção adsortiva do enxofre à $313 \mathrm{~K}$.

\begin{tabular}{|c|c|c|c|c|}
\hline \multicolumn{5}{|c|}{ Pseudoprimeira ordem } \\
\hline & $k_{1}\left(\min ^{-1}\right)$ & $q_{e \text { calc }}\left(\mathrm{mg} \mathrm{g}^{-1}\right)$ & $q_{e} \exp \left(\mathrm{mg} \mathrm{g}^{-1}\right)$ & $\mathrm{R}^{2}$ \\
\hline HZSM35 & $5,56 \times 10^{-3}$ & 1,60 & 1,79 & 0,986 \\
\hline 2,5MoZSM35 & $7,41 \times 10^{-3}$ & 1,45 & 1,12 & 0,977 \\
\hline 5MoZSM35 & $5,5 \times 10^{-3}$ & 1,67 & 2,26 & 0,990 \\
\hline \multicolumn{5}{|c|}{ Pseudossegunda ordem } \\
\hline & $k_{2}\left(\right.$ g.mg $\left.\min ^{-1}\right)$ & $q_{e \text { calc }}\left(\mathrm{mg} \mathrm{g}^{-1}\right)$ & $q_{e \exp }\left(\mathrm{mg} \mathrm{g}^{-1}\right)$ & $\mathrm{R}^{2}$ \\
\hline HZSM35 & $8,02 \times 10^{-2}$ & 2,14 & 1,79 & 0,984 \\
\hline 2,5MoZSM35 & $4,57 \times 10^{-2}$ & 2,01 & 1,12 & 0,728 \\
\hline 5MoZSM35 & $1,98 \times 10^{-2}$ & 2,57 & 2,26 & 0,991 \\
\hline \multicolumn{5}{|c|}{ Difusão intrapartícula } \\
\hline & $k_{D I F}\left(\mathrm{mg} \cdot \mathrm{g}^{-1} \cdot \mathrm{min}^{-0,5}\right)$ & $C\left(\mathrm{mg} \mathrm{g}^{-1}\right)$ & $\mathrm{R}^{2}$ & \\
\hline HZSM35 & $7,45 \times 10^{-2}$ & 0,15 & 0,998 & \\
\hline 2,5MoZSM35 & $7,80 \times 10^{-2}$ & 0,13 & 0,948 & \\
\hline 5MoZSM35 & $8,20 \times 10^{-2}$ & 0,46 & 0,997 & \\
\hline \multicolumn{5}{|c|}{$\begin{array}{l}\text { Elovich } \\
\end{array}$} \\
\hline & $\alpha\left(\mathrm{mg} \mathrm{g}^{-1} \min ^{-1}\right)$ & $\beta\left(\mathrm{g} \cdot \mathrm{mg}^{-1}\right)$ & $\mathrm{R}^{2}$ & \\
\hline HZSM35 & $2,22 \times 10^{-1}$ & 0,436 & 0,975 & \\
\hline 2,5MoZSM35 & $4,86 \times 10^{-1}$ & 0,095 & 0,978 & \\
\hline 5MoZSM35 & $3,57 \times 10^{-1}$ & 0,487 & 0,981 & \\
\hline
\end{tabular}

Para o processo de adsorção à $303 \mathrm{~K}$, os dados experimentais da amostra 2,5MoZSM35 ajustaram-se melhor ao modelo de pseudoprimeira ordem, com um coeficiente de correlação igual a 0,971 e $q_{\text {ecalc }}$ igual a $1,10 \mathrm{mg} / \mathrm{g}$, próximo ao valor de $1,12 \mathrm{mg} / \mathrm{g}$ obtido experimentalmente. Os dados das amostras HZSM35 e 5MoZSM35, para a mesma temperatura, tiveram um melhor ajuste ao modelo de pseudossegunda ordem com o $\mathrm{R}^{2}$ igual a 0,991 e 0,985 respectivamente, sendo que este último não foi o maior valor do coeficiente de correlação da amostra, mas a avaliação do valor do $q_{\text {ecalc }}$ próximo ao valor experimental foi determinante para o ajuste do modelo.

Para o processo de adsorção à $313 \mathrm{~K}$, os dados experimentais das amostras HZSM35 e 2,5MoZSM35 obtiveram melhores ajustes ao modelo de pseudoprimeira ordem, com coeficientes de correlação igual a 0,986 e 0,977 respectivamente, enquanto que para a amostra 5MoZSM35 o modelo de pseudossegunda ordem obteve melhor ajuste com o $\mathrm{R}^{2}$ igual a 0,991 e $q_{\text {ecalc }}$ igual a $2,57 \mathrm{mg} / \mathrm{g}$.

Com exceção da amostra 2,5MoZSM35(303K) todos tiveram um bom ajuste ao modelo de Elovich, com valores de $\mathrm{R}^{2}$ maiores que 0,9. O modelo de Elovich é utilizado para explicar a ocorrência de adsorção em sólidos com superfícies energeticamente heterogêneas, sendo assim, pode-se inferir o grau de heterogeneidade dos adsorventes estudados influenciou o processo de adsorção do enxofre, o que pode ser explicado pela possível heterogeneidade na dispersão do molibdênio na superfície desses sólidos.

Apesar do modelo de difusão intrapartícula apresentar coeficientes de correlação perto da unidade para parte dos sistemas adsortivos avaliados, este mecanismo não deve ser determinante, visto que a reta do modelo ajustado aos dados experimentais não passa pela origem, então podese determinar que este mecanismo não é a etapa determinante do processo [19] e que outros mecanismos atuam no controle da adsorção.

\section{CONCLUSÃO}

A partir da análise dos resultados obtidos, pode-se destacar que a inserção do Mo na estrutura da zeólita variou a estabilidade térmica do sólido, sendo que o incremento em 2,5\% de Mo aumentou essa estabilidade em comparação com a amostra pura (HZSM35). Pode-se observar que incremento no teor de molibdênio na composição do adsorvente influenciou diretamente nas características físicas apresentadas por esses materiais e na sua capacidade de adsorção. Os 
resultados também mostraram que capacidade de adsorção está diretamente relacionada à temperatura do processo, sendo que para a temperatura de $303 \mathrm{~K}$ pode-se observar que os sistemas apresentaram a seguinte ordem de adsorção: HZSM35>5MoZSM35>2,5MoZSM35 e para a temperatura de $313 \mathrm{~K}$ a capacidade de adsorção apresentou o seguinte comportamento: 5MoZSM35>HZSM35>2,5MoZSM35. Por fim, pode-se concluir que a aplicação desses adsorventes para remoção de compostos sulfurados apresenta viabilidade, e pode ser utilizado para complementar os processos tradicionais na remoção de compostos de enxofre recalcitrantes.

\section{AGRADECIMENTOS}

Os autores agradecem à Coordenação de Aperfeiçoamento de Pessoal de Nível Superior (CAPES), a Agência Nacional do Petróleo (ANP), ao Programa de Pós-Graduação em Engenharia Química (PPGEQ) da UFRN e aos departamentos de Química (DQ) e Engenharia Química (DEQ) da Universidade Federal de Sergipe.

\section{REFERÊNCIAS BIBLIOGRÁFICAS}

1. Yang RT, Hernández-Maldonado A, Yang FH. Desulfurization of transportation fuels with zeolites under ambient conditions. Science. 2003;301, doi:10.1126/science.1085088.

2. Aparicio F, Camú E, Villarroel M, Escalona N; Baeza P. Deep Desulfurization by adsorption of 4,6dimethyldibenzothiophene, study of adsorption on different transition metal oxides and supports. J Chil Chem Soc. 2013;58(4), doi:10.4067/S0717-97072013000400034.

3. Javadli R, Klerk A. Desulfurization of heavy oil. Appl Petrochem Res. 2012;1:3-19, doi:10.1007/s13203-012-0006-6.

4. Xiao T, York APE, Al-Megren H, Claridge JB, Wang H, Green MLH. Preparation of molybdenum carbide-based catalysts for deep HDN. C R Acad Sci, Ser IIc: Chim. 2000;451-458, doi:10.1016/S13871609(00)01154-3.

5. Song H, Yang G, Song H, Cui X, Li F, Yuan D. Kinetic and thermodynamic studies on adsorpion of thiophene and benzothiophene onto AgCeY zeolite. J Taiwan Inst Chem Eng. 2016;63:125-132, doi:10.1016/j.jtice.2016.02.020.

6. Muzic M, Sertic-Bionda K, Gomzi Z, Podolski S, Telen S. Study of diesel desulfurization by adsorption. Chem Eng Res Des. 2010;88:487-495, doi:10.1016/j.cherd.2009.08.016.

7. Takahashi A, Yang FH, Yang RT. New Sorbents for Desulfurization by $\pi$-Complexation: Thiophene/Benzene Adsorption. Ind Eng Chem Res. 2002;41 (10):2487-2496, doi:10.1021/ie0109657.

8. Furimsky E. Catalytic Hidrodeoxygenation. Appl Catal A. 2000;199(2):147-190, doi:10.1016/S0926$860 \mathrm{X}(99) 00555-4$.

9. Mohamed ME, Al-Yacoub ZH, Vedakumar JV. Biocatalytic desulfurization of thiophenic compounds and crude oil by newly isolated bacteria. Front Microbiol. 2015;6(112), doi:10.3389/fmicb.2015.00112.

10. Maass D, Todescato D, Moritz DE, Oliveira JV, Oliveira D, Souza AAU, Souza SMAG. Desulfurization and denitrogenation of heavy gas oil by Rhodococcus erythropolis ATCC 4277. Bioprocess Biosyst Eng. 2015;38:1447-1453, doi:10.1007/s00449-015-1386-7.

11. Ismail W, El-Sayed W, Raheem ASA, Mohamed ME, El Nayal AM. Biocatalytic desulfurization capabilities of a mixed culture during non-destructive utilization of recalcitrant organosulfur compounds. Front Microbiol. 2016;7(266), doi:10.3389/fmicb.2016.00266.

12. Cedeño-Caero L, Ramos-Luna M, Méndez-Cruz M, Ramírez-Solís J. Oxidative desulfurization of dibenzothiophene compounds with titania based catalysts. Catal Today. 2011;172:189-194, doi:10.1016/j.cattod.2011.01.048.

13. Cedeño-Caero L, Martínez-Abarca E, Gómez-Díaz M, Pedraza-Archila F. Desulfuración de organoazufrados presentes en diesel por oxidación y extracción. Parte.I. Catalizadores de cobre soportados. Rev Mex Ing Quím. 2005;4(3):241-252.

14. Giuseppe AD, Crucianelli M, Angelis FD, Crestini C, Saladino R. Efficient oxidation of thiophene derivatives with homogeneous and heterogeneous MTO/H2O2 systems: A novel approach for, oxidative desulfurization (ODS) of diesel fuel. Appl Catal B. 2009;89(1):239-245, doi:10.1016/j.apcatb.2009.02.009.

15. Sun H, Sun L, Li F, Zhang L. Adsorption of benzothiophene from fuels on modified NaY zeolites. Fuel Process Technol. 2015;134:284-289, doi:10.1016/j.fuproc.2015.02.010. 
16. Silva AOS. Síntese e caracterização de catalisadores de fero e cobalto suportados nas zeólitas HZSM12 e HZSM-5 para a conversão de gás de síntese em hidrocarbonetos. [Tese], Natal (RN): Universidade Federal do Rio Grande do Norte; 2004. 229p.

17. Lagergren S. On the theory of so-called adsorption dissolved substances. Handl. 1898;24:1-39.

18. Ho YS, Mckay G. Comparative sorption kinetic studies of dye and aromatic compounds onto fly ash. J Environ Sci Health. 1999;34(5):1179-1204, doi:10.1080/10934529909376889.

19. Weber WJ, Morris JC. Kinetics of adsorption on carbon from solution. J Sanit Eng Div ASCE. 1963;89:31-60.

20. Elovich SY, Zahbrova GM. Mechanism of the catalytic hydrogenation of ethylene on nickel. I. Kinetics of the process. Phys Chem.1939;13:1761-1764.

21. IZA - Internacional Zeolite Association [Internet] [Acesso em 08 jul 2017]. Disponível em http://www.iza-online.org/synthesis/Recipes/XRD/ZSM-35.jpg.

22. Silva BJB, Silva AOS, Neto PPM, Costa TPM, Júnior LVS, Ribeiro LMO, Alencar SL, Silva AE, Santos RB. Análise quantitativa das zeólitas ferrierita, ZSM-5 e mordenita presentes em amostras sintetizadas. Cerâmica. 2015;61(357):14-22, doi:10.1590/0366-69132015613571842.

23. Wang L, Tian P, Yuan Y, Yang M, Fan D, Zhou H, Zhu W, Xu S, Liu Z. Seed-assisted synthesis of high silica ZSM-35 through interface-induced growth over MCM-49 seeds. Microporous Mesoporous Mater. 2014;196:89-96, doi:10.1016/j.micromeso.2014.05.001.

24. Pergher SBC, Miotto N, Bresolin D, Vaclavik FD, Oliveira CR, Baibich IM. Síntese da zeólita ZSM35 e avaliação catalítica na decomposição do NO. Rev Perspect. 2014;38(143):71-79.

25. Oliveira TG, Machado SWM, Santos SCG, Souza MJB, Pedrosa AMG. Adsorção de $\mathrm{CO}_{2}$ em peneiras moleculares micro e mesoporosas. Quím Nova. 2014;37(4):610-617, doi:10.5935/01004042.20140101.

26. Treacy MMJ, Higgins JB, Von Ballmoos R. Collection of simulated XRD powder patterns for zeolites, $3^{\text {rd }}$ ed. New York: Elsevier; 1996. 586p.

27. Montañez MK, Molina R, Moreno S. Nickel catalysts obtained from hydrotalcites by coprecipitacion and urea hydrolysis for hydrogen production. Int J Hydrogen Energy. 2014;39:8225-8237, doi:10.1016/j.ijhydene.2014.03.103.

28. Barros ICL. Estudo e aplicação dos sistemas ZSM-5 contendo nióbio [Tese], Brasília: Universidade de Brasília; 2007. 168p.

29. Yu SY, Garcia-Martinez J, Li W, Meitzner GD, Iglesia E. Kinetic, infrared an X-ray absorption studies of adsorption, desorption, and reactions of thiophene on H-ZSM5 and Co/H-ZSM5. Phys Chem Chem Phys. 2002;4:1241-1251, doi:10.1039/b108640p.

30. Al- Yassir N, Mao RLV. Physico-chemical properties of mixed molybdenum and cerium oxides supported on silica-alumina and their use as catalysts in the thermal-catalytic cracking (TCC) of $n$ hexane. Appl Catal A. 2006;305(2):130-139, doi:10.1016/j.apcata.2006.02.054. 